\title{
Full inclusion of a student with visual impairment over the full Physical Activity and Sport Sciences Degree: A case study
}

\author{
Raul Reina ${ }^{1}$ and Javier Alvaro-Ruiz ${ }^{2}$ \\ ${ }^{1}$ Miguel Hernández University, Elche (Spain) \\ ${ }^{2}$ Graduate in Physical Activity and Sport Sciences and member-seller of ONCE
}

\begin{abstract}
This paper explains the inclusion process done with a student with a severe visual impairment in Physical Activity and Sports Sciences Degree. This inclusion process required a close collaboration with professionals and social workers such as the family, the Spanish National Organization for Blind People (ONCE), the university Service for students with disabilities, faculty managers, professors and the student's peers. The student did the admission exam (theory and practical) in similar conditions to his classmates and specific adaptations were arranged. This case study paper is organized following the next group of actions: a) theory subjects, b) practical and sport subjects, c) adapted physical activity and the double inclusion paradigm, d) evaluations, and e) professional training. The inclusion of this student has been experienced as a great value for his classmates education and to date he is the only student with a severe visual impairment that has finished this studies in Spain.
\end{abstract}

Key words: inclusion, blindness, sport sciences, physical activity, adaptations

\section{Introduction}

The European Union states that the social inclusion is a process that assures people in poverty risk and social exclusion may grow their possibilities and necessary resources to participate actively in the economic, social and cultural life and, at the same time, enjoy better conditions of life and social welfare that are considered common in the society where they live (Ríos et al., 2009). There are many meanings and variations that inclusion adopts in physical activities and adapted sports, but we could consider the inclusion as the process where people with disability share the same space, materials and activities as their peers (Rouse, 2009). So, inclusive physical activity is the philosophy and practise that assures that everyone, apart from his age and skill, has the same opportunities to practise physical activity (Kasser \& Little, 2005).

In accordance with Article 31 of the United Nations Convention about the rights of persons with disabilities, adults and children with disability must have access to spare time activities, entertainment and sport in inclusive areas as specific ones (U.N., 2006). This international law is developed in the Spanish Official Bulletin of $21^{\text {st }}$ April (2008), complying the mentioned article of United Nations about participation in cultural life, entertainment activities, recreation and sport. In this way, other actions of good practice have been conducted in Spain in recent years (Perez-Tejero, 2013; Spanish Paralympic Committee, 2014). Some of the recommendations suggested to achieve this goal are: a) to stimulate and promote the participation of people with disabilities in general sport activities; b) to assure that people with disability have the opportunity to organize and develop sport and leisure activities; c) to assure that people with disability have access to sport, entertainment and tourists facilities; d) to assure that children with disability have the same access than the rest of children in participation of entertainment and ludic activities and sport, including those realized in the school system; e) to assure that people with disability have access to the services when participating in the organization of these activities. 
According to some authors who have undertaken the inclusive process in physical education (Block \& Obrusnikova, 2007) and other physical activity and sport contexts (DePauw \& Doll-Tepper, 2000; Pérez-Tejero, 2013), we found some postulations related with participants in inclusive activities; like everyone is unique with different abilities and physical, cognitive, emotional and social necessities; everyone has the right to take advantage of inclusive physical activities; people's skills vary and they are the result of the relationship among the participants, the practical context and the activities; realized users have the right to choose and take their own decisions; or that everyone can take advantage of the experience from others. So, the advantages of inclusive practices have been widely reported by their users such as: respect of individual differences and skills, a deeper knowledge of own strengths and weaknesses (Lindsay, McPherson, Aslam, McKeever, \& Wright, 2013), a great spectrum of opportunities and experiences (Block, Taliaferro, Campbell, Harris, \& Tipton, 2011), developing resources to avoid isolation, increasing acceptation and community feelings (Suomi, Collier, \& Brown, 2003), contributing to the achievement of objectives and programme results, or increasing the individual value and self-control (Martin \& Smith, 2002). One of the key factors for successful inclusion is a favorable social environment, which includes a positive attitude from social agents, such as teachers, peer students and parents.

Visual impairment has been considered one of the most threatening disabilities, typically awakening emotional reactions of extreme loss of confidence and independence in individuals confronted with this disability. General education teachers have identified students with visual impairment as the students they would have less interest to have in their classroom (Horne, 1983), generally demonstrating negative attitudes towards the inclusion of those students (Wall, 2002). As the visual sense is the most common of the spatial awareness and sensorimotor feedback systems, its loss or impairment may cause significant participation restrictions within physical activity contexts such as ball and tag games (see Lieberman, Robinson, \& Rollheiser, 2006).

Physical Activity and Sport Sciences (PASS) Studies at the Miguel Hernandez University (UMH: Elche, Spain). The PASS studies in the UMH were taught originally in the academic course 2005/06 in the Social and Legal Sciences Faculty in Elche, although nowadays it is taught in the Sociosanitary Sciences Faculty since the academic course of $2008 / 09$. This faculty is located in the southeast of Spain, and its objective is not only to offer the best quality in basic subjects that defines the education programme, but also to realize a specific training in those itineraries that show better future perspectives about the needs in the professional world and the social context. The PASS study plan was divided in two cycles of 3 and 2 years respectively, although at this moment the grade is over a period of 4 years due its adaptation to the Bologna's Agreement for European Universities. However, the study program followed by the target student comprises 300 credits in a 5-year program, including 4.5 credits in adapted physical activity and adapted sports.

The core of the proposed subjects is to achieve a balance between basic and specific knowledge when the students graduate in PASS, i.e.: a training orientated to the labour market. The disciplines of the first work cycle provide to students basic understanding of human movement from a multidisciplinary perspective: to foster 1) understanding the aim of the studies; 2) applied scientific basis; 3) physiological and biomechanical basis; 4) behavioural and social factors; 5) understanding the effects of physical exercise in structures and functions of the human being; 6) to understand the effects of physical exercise on physiological and social domains; 7) basic patterns and skills of human movement; and 8) basis of individual and team sports. All those goals mentioned above (from 1 to 8) are considered as knowledge goals, with an overall training of 180 credits ( 3 years x 60 credits). 
On the second cycle, a common applied training is offered, where the student has to know and applicate professional competences from different professional fields: sport training, sport teaching and physical education, physical activity and health, sport management and sport leisure. The training objectives were: 9) design, develop and evaluate the teaching process related to physical and sport activity, with attention to people's individual characteristics; 10) to promote and evaluate the development of lasting and autonomous habits in physical and sport activity practise; 11) to plan, develop and control training processes at different levels; 12) to apply physiological, biomechanical and social principles to different physical and sport activity fields, 13) to evaluate physical condition and prescribe healthy physical exercises; 14) to identify health risks due to inadequate physical activities; 15) to plan, develop and evaluate the realization of physical/sport activity programs adapted to different populations; 16) to manage programmes for organizations, sport institutions and facilities; and 17) to know how to use materials and sport equipment. Goals 9 to 17 are skills applied to the professionals fields, organized in two years of 60 credits each one. The last year, the students have 12 credits $(120 \mathrm{~h})$ in a practical context, plus 18 free/optative credits.

This paper is a case study which explores the process followed over six years in the $\mathrm{UMH}$, regarding the inclusion of a student with a severe visual impairment in the Degree of Physical Activity and Sport Sciences
(PASS). According to Thomas and Nelson (2001), the case study consists of an intensive study of a single unit, providing insight and knowledge of a general nature for improved practices. Observations, interviews, and documents are used to describe the followed process.

\section{Methods}

\section{Target case}

Javier was a young male student, who started PASS' studies with $18 \mathrm{yr}$ and finished with $22 \mathrm{yr}$ old, with a severe visual impairment from birth. He performed his primary and secondary studies in an inclusive school, counting on the continued support of professionals from the Spanish National Organization for Blind People (ONCE). He practiced some adapted sports (i.e. goalball and athletics) until he was 14 years old, and with his arrival to the secondary school he started competition in football-5-a-side at national level. He is actually classified as B1 according IBSA classification rules, which define B1 players as ones that have a visual acuity poorer than LongMAR 2.60 (De Salvia, 2012).

The inclusion process conducted in the university required a close collaboration between the family, ONCE, the Service for students with disabilities, faculty managers, professors and the students' peers (Figure 1). We can consider this process as a good practice case, with a student who has overcome environmental barriers due to his strong desire to study at this college. 
Figure 1. Stakeholders that took part in the inclusion process and their main roles

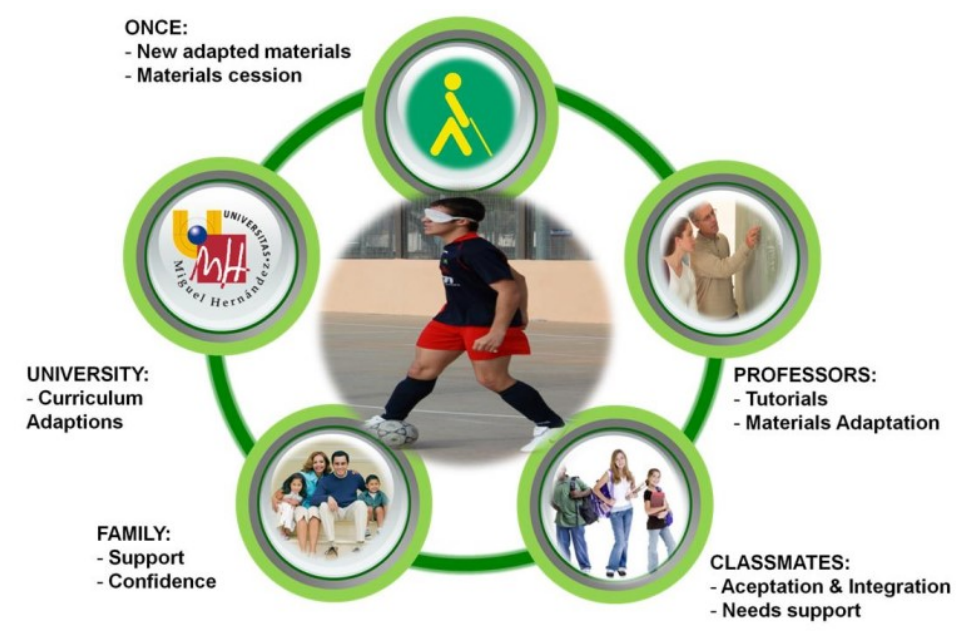

Admission: Assessment of physical skills

In order to make the decision to start PASS by Javier, a meeting was organized with the responsible of the Service for students with disabilities at the UMH, managed by a professor specialist in adapted physical activity (co-author of this paper), an assistant professor from ONCE, the parents of the student and the student himself (co-author of this paper). During this meeting (September 2008, just before to start the last academic year at the secondary school) the possibilities to do or not the Degree were discussed and SWOT (Strength, Weakness, Opportunities and Threats) analysis was carried out, resulting in the student began his studies in the academic year 2009-10.

As facilitators, we counted with several positive factors such as the strong desired by the student to perform this specific studies; his motivation and his enthusiasm for sport and the internal support from the University staff but also the external support from parents, friends, etc. In the words of Javier: "the decision was very clear to me. I have been an athlete all my life, and since in high school the physical education classes were what I liked most, I wanted to choose a path that allow me to keep in contact with athletes and sport, instead of seeking for a potential studies that would bring me to find an easy job limited by my visual impairment".

Additionally, his mother (Luisa, 56 years old) explained that "when Javier told us he wanted to study Sports Sciences I could not believe it: was not enough for him his visual impairment that he still wanted to make his life more difficult? ......we had always instilled in Javier that one has to fight for one's dreams, and the difficulty of life lies on the low willingness to confront it. And he just did that, Javier told us that what makes him happy was the sport and its environment, and this was sufficient reason to try it."

On the contrary, several barriers were identified as the difficulty in finding an inclusive job in the future; the expected quantity of adaptations needed to follow the courses; the dependence on transport in order to travel to the university, or moving within the university campus where there were several areas under construction (i.e, lack of fixed orientation points), or the negative opinions that some sceptical university staff had about his enrolment in the Degree.

\section{Adaptations and Modifications in Physical Skill Assessments}

All candidates interested on access to the PASS Degree are required to success a physical skills assessment. In order to promote the inclusion perspective from day one, Javier performed the same required tests with some modifications, previously assisted by the specialist teacher in adapted physical activity in July 2009. Therefore, the student performed the following tests: 
- Swimming test. This test consisted of completing a distance of $50 \mathrm{~m}: 25 \mathrm{~m}$ freestyle (crawl) and $25 \mathrm{~m}$ backstroke. The adaptation was to provide verbal information to the student regarding where the style had to be changed (swimming in a lane next to the examiner) and touching the student with a softened device (similar to Paralympic Swimming) when he was close to the arrival.

- Ball skill test. This test originally consisted in completing a circuit doing zig-zag between five cones bouncing a volleyball ball, doing three throws inside of a circumference (on a wood platform) from a distance of $2.5 \mathrm{~m}$, doing three ball kicks in a square of $2 \times 1 \mathrm{~m}$, and doing the way back dribbling the ball with the feet. The necessary adaptations involved the elimination of the bouncing due to the difficulties with aerial trajectories, and he did all the circuit dribbling an official blind-football ball. The cones were replaced by examiners, increasing the distance from 2 to $3 \mathrm{~m}$, and they indicated verbally the position of each one.

- Medicinal ball throwing. This test was done with the same ball weight than the rest of male candidates $(5 \mathrm{~kg})$ and the throwing square was adapted with a relief-throwing box.

- Speed $50 \mathrm{~m}$. Student used 2 lanes and was verbally assisted by a guide with a call technique.

- Endurance $2000 \mathrm{~m}$. It was requested a guide to perform the entire test with the student using the guide rope technique.

The adaptations previously indicated, plus an extra time bonus provided in some tests, were carried out in order the student could complete the five tests and get the aptitude to university entrance in PASS.

\section{Adaptations and Modifications in Theoretical Courses}

When Javier began his courses in PASS, a commission to monitor his progress was appointed. This commission was formed by two professors: the specialist professor in adapted physical activity and a team sports professor, who was also the student's football coach. Other meetings were done with the rest of the professors involved in each academic year, to give them specific information to support them regarding: how to design accessible teaching materials, providing materials in advance, individual planning tutorials in the most complex subjects (i.e. biomechanics), or develop communication strategies in theoretical and practical sessions. Direct work with the professors made it unnecessary to turn to the Service for students with disabilities, promoting the inclusive student process. In this process, two main social agents helped: i) the ONCE, providing loan relief materials (i.e. human anatomy patterns); and ii) university printing services, providing the transcription of print materials to be read by Jaws software or similar (voice speaker).

In general, the student seated in the classroom close to a classmate that assisted him in the explanation of the visual contents provided by professors on the board or by a PowerPoint presentation. The student also had available (before each class) a schema of the professor's presentations. The main problem here was how to communicate the visual contents, such as graphs or specific human/sport movements. In order to cope with this problem, several scale models were developed. Also, it was used drawing rubber for tutorials and lessons and peer-tutors. The learning of the technical sport movements was often made by the use of modelling where the professor or peer-tutor reproduced the movement moving the student's limbs. Therefore, with this information and more analytic learning strategy, the student followed the lessons.

All these strategies were discussed during some faculty meetings attended by all professors from the PASS Degree. In the third academic year, the adaptations and the interaction between student-professors was completely natural, responding to the student needs any time, without the support of the Service for students with disabilities or the appointed commission to ensure Javier's inclusion. In words of Javier's mother: "the 
real inclusion of Javier during the PASS studies started when I was convinced that he did the same than his classmates with only the necessary modifications to "turn his ears in his eyes". I have to say it was not easy, but the motivation of the professors to face this beautiful challenge it make it easy. Javier attend to all the tutorials that he needed and at some moments I thought that only we needed to sleep at the university, because we were more time there than at our home. He studied hard, he strove much, and he required help only when it was necessary; he never wanted a favourable treatment, because he was convinced about he could do everything as his classmates".

\section{Adaptations and Modifications in Practical Courses}

Sixty credits $(33 \%)$ of the first cycle are specific courses where practical skills are required. To pass those courses, the students must demonstrate basic knowledge about different sports regarding: rules game, basic teaching and training methodology, and develop basic skills in order to practice those sports. The sport courses, with a high practical component, were a challenge in this inclusive process and maybe one of the most satisfactory outcomes:

- Rhythmic gymnastics (1st year): Adaptations of apparatus (i.e. hoop with a bell), use of guidance elements in the space and verbal feedback and feedforward. The student was able to perfom a rhythmic choreography individually and with a group of students.

- Athletics (1st year): similar adaptations to para-athletics (i.e. guide technique). However, the student was able to learn some techniques without any adaptations, such as pole vault that implies complex movements.

- Team sports (2nd year). In football, he did not have any problem for his inclusion because he is a regular football player. Some small adaptations carried out were the use of a sound ball, guide techniques and the introduction of specific rules such as "I am going" to avoid collisions with other players in the field. In order to play basketball, handball or rugby, where also the court is shared by both teams and there are aerial trajectories, it was used magnetic boards done by ONCE to explain tactics, the specific technical movements were learned in small groups with the help of peer tutoring, it was used a sound ball and some game rules were modified. For example, in volleyball, when the professor explained some tactics or rules contents, he used the magnetic board, with a scaled and relief volleyball field (Figure 2a): players in positions 2-3-4 had one shape (attackers), and players in positions 1-6-5 had another one (defenders); the player responsible of the second contact was represented with a different head to identify his/her position on the board. The ball was made with other (smaller) shape. During the practical sessions, there were developed different strategies such as: analytical learning techniques (supported by the professor and a Javier's classmate), suspended balls and embossed markings on the floor (Figure $2 b$ ), individual support by the professor or peers tutoring explaining the same players movements on the magnetic board. The student learned the main volleyball techniques, i.e.: finger touch, forearms technique, service and smash, and he participated in collective situations performing the action of serve. 
Figure 2. Adapted materials (A) and peer-tutoring technique learning (B) in volleyball.

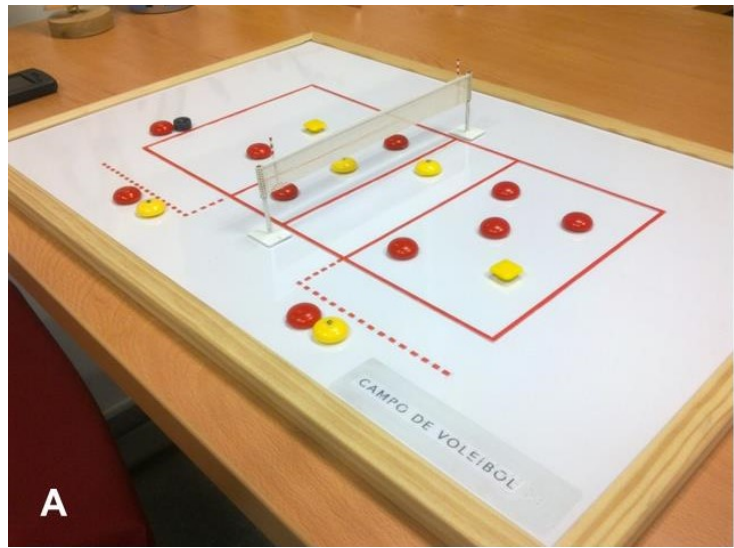

- Tennis (3rd year): The student worked the Pal-IN or adapted tennis, which consists in the use of a sound adapted tennis ball in a modified size court. The use of extra bounces was also allowed, practicing some strokes in front of a wall or using hanging balls.

- Golf (3rd year): One model of a practice golf field in UMH was built, and the student was able to do all the activities with guide techniques.

- Judo (3rd year): This sport did not present any challenge for Javier as there is a Paralympic modality orientated for this population.

- Cycling (3rd year): The student had a tandem bike that the ONCE lent to the university.

Although in some team sports that had aerial trajectories the full inclusion was limited, the student was able to acquire the competences in these subjects thanks the design small game situations. New materials and adapted equipment were designed and we

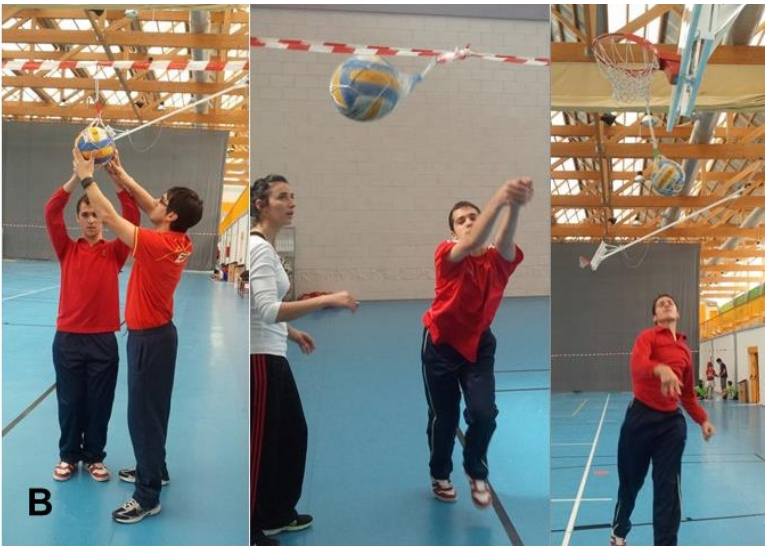

developed teaching activities never done before.

\section{The "double inclusion"}

In the fourth year, the student participated in the course of adapted physical activity and sports for people with visual, hearing, physical and intellectual impairments. The program included practical sessions of inclusion activities for these populations and the following sports: goalball, Paralympic football-5-a-side, wheelchair sports, sitting volleyball, boccia, para-athletics, and Special Olympics sport program. Following the principle of normalization, in which we have the regular curriculum as the last reference, we promoted Javier's autonomy as much as possible. The student sat on the floor like his peers to play sitting volleyball (Figure 3a), with an activity limitation of his lower or upper limbs (Figure 3b); using a wheelchair (Figure 3c), simulating hearing loss, using crutches, limitating hand functions, among others. 
Figure 3. Teaching activities in adapted physical activity subject: sitting (A), limited arm movement (B), wheelchair (C)
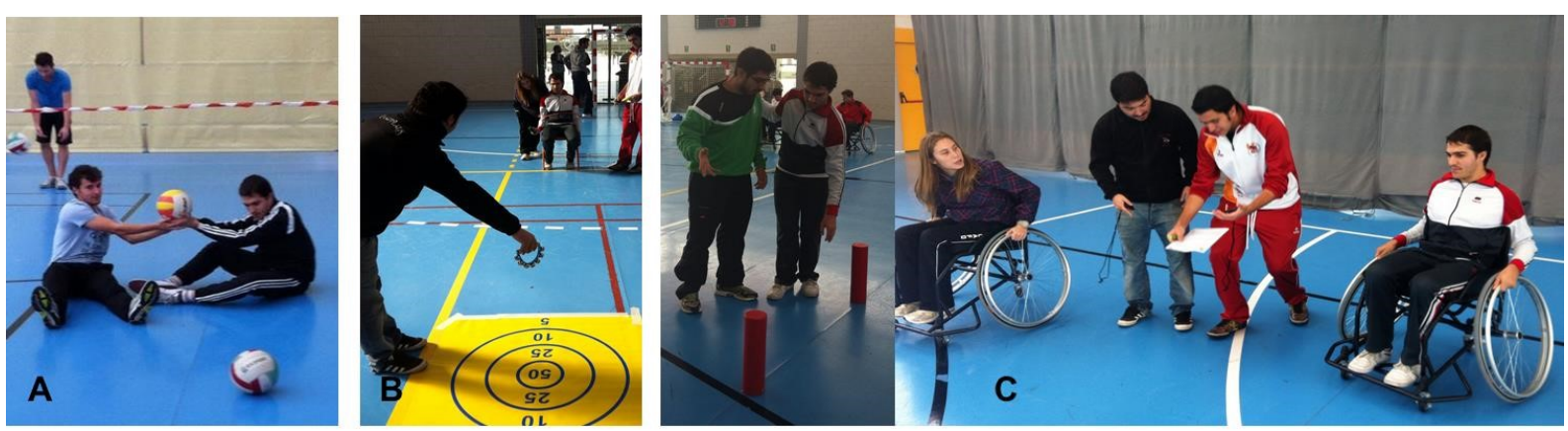

Moreover, the student's group, who had to design a project related with the course contents, designed a petanque adaptation for visual impairment where rules were adapted as follows (Soler, Álvaro, Cammidge, González, Ferrer, \& Reina, 2013):

- The jack, using a ball that emits an intermittent sound even when it is not in movement, allowing its localization and orientation during the whole game.

- A touching board. The player can organize the pitch by squares, helping to know where the balls are (two types of objects are used to distinguish between rival balls), and allowing to know how and where to throw the ball.

- The field of play. The original pitch was used, adding a series of small squares of the same size that are represented on the board. This adaptation does not interfere with the regular game, making easier to play this sport in any facility.

The program was conducted with players with and without visual loss, and some adaptations of the rules were added like the use of blindfolds by all the participants (Figure $4 a)$. The sport was played in a real context in Elche city by people of different ages, from kids to elderly.

Figure 4. Materials and development of adapted petanque (A); adapted template during team sports evaluation (B)
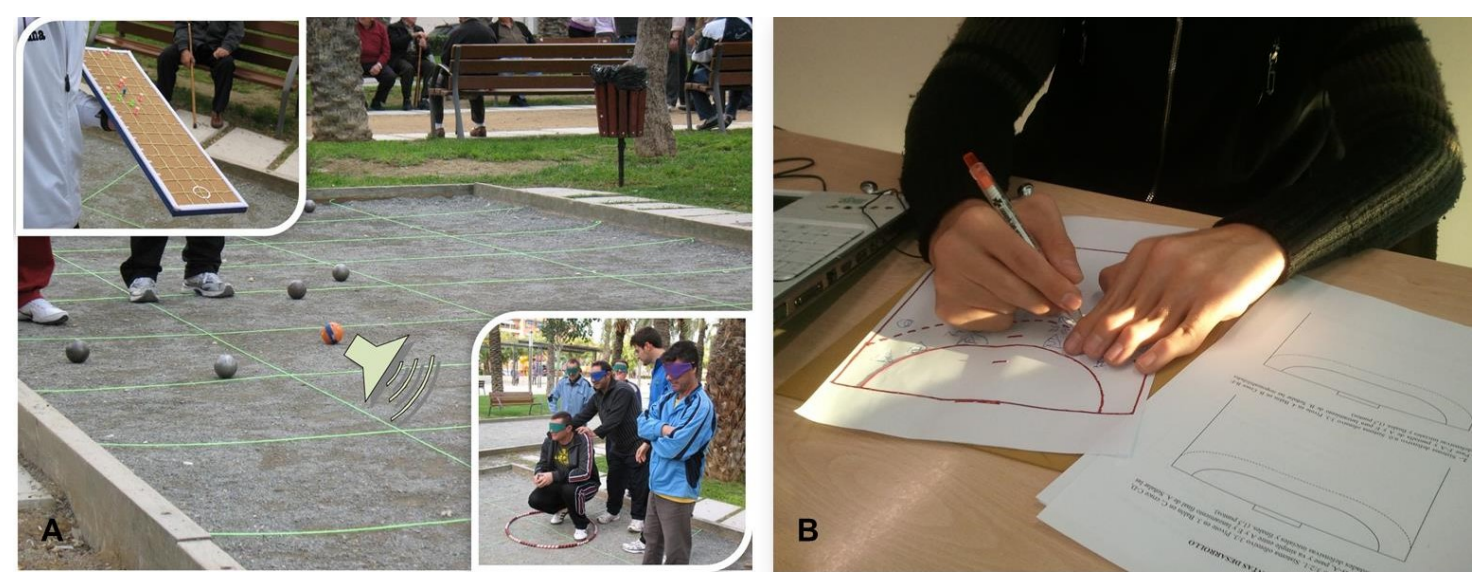
Adaptations and Modifications in Examination

Regarding examinations, all professors came to an agreement to allow Javier to use his own computer (with a voice interface) and providing longer examination time. The exams were done in an accessible document (MS Word) and the student answered the questions in the same document, which was removed later from the student's computer by the professor. For the practical content exams, the same material and access elements in class were used, such as rubbers, relief patterns (Figure 4b), etc.

\section{Professional training}

Javier has done his professional training in the Spanish Association of Adapted Physical Activity and Adapted Sports (AEDAFA). He was the responsible for the following tasks: i) managing the content of the website; ii) checking the website accessibility; iii) direct participation in activities to promote disability awareness in some primary and secondary schools; and iv) cooperating as a research fellow in projects about awareness intervention to improve attitudes toward inclusion in physical activity based on simulation, curriculum, multimedia and contact strategies (Lindsay \& Edwards, 2013). Also, he was involved in the organization of the European Conference of Adapted Physical
Activity (EUCAPA 2014): i) assisting the scientific committee in the peer review process of the submitted abstracts; and ii) book of abstracts layout.

His enthusiasm and love for sport helped to develop awareness activities in primary and secondary schools, involving teammates from his blind-football team. Actually, he is member of the Spanish national team, and he participated in the last World Championships (Japan, November 2014) and the European Championships (Hereford, Great Britain, August 2015). He also receives a sport grant as an elite athlete from the Trinidad Alfonso Foundation, a private program in the Valencian Community, with the same grants for Olympic and Paralympic athletes. Also, he is a potential worker for the ONCE's sports policy, leading some projects to promote physical activity and sports among young people with visual impairments. He is also still cooperating with some awareness interventions and physical education teachers' training by a project conducted by UMH in cooperation with Spanish Paralympic Committee and Trinidad Alfonso Foundation (Sierra-Marroquín, Reina, García-Gómez, Hemmelmayr, \& Fernández-Pacheco, 2016) (Figure 5).

Figure 5. Javier in a teaching action with physical education professors

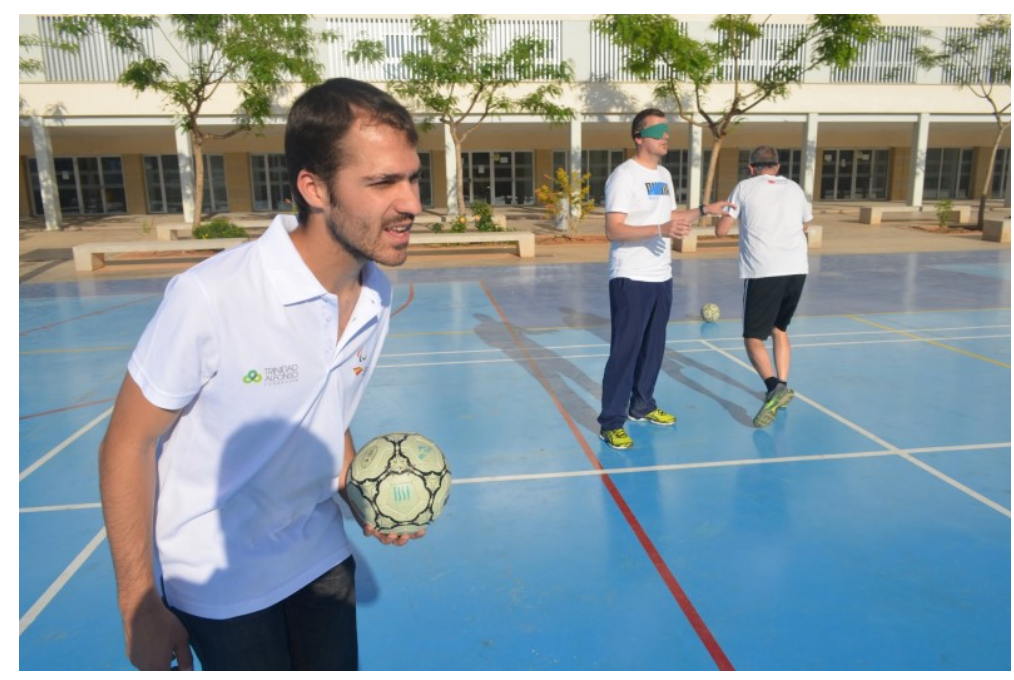


Javier explains his 5 years of study as: "from the beginning, my inclusion was a fact. Many situations were new for me, but I liked it; therefore, whatever it was necessary to be done (group work, study group, passing notes, participate in exhibitions, etc.)... I tried to do my best adapting myself as just one more in class. This attitude was valued highly by my classmates as it was very novel situations for them, and therefore very exciting for all of us. Additionally, since day one, I also participated in all leisure activities in the most normalized way possible, which led to develop a positive attitude of my peers toward my disability, so they were the ones that often proposed solutions for me in order to participate in equal conditions".

Also, his mother mentioned that: "It was a five year career and he succeeded course by course. I have witnessed how my son invested many hours preparing notes, papers, exams ... there were many ups and downs and many times the fatigue played hard on him. What we can do in five minutes, people with visual impairment need an hour... for example, they only need to look around to fast orient ourselves, and my son needed more time. However, despite those constrains, Javier showed us that effort is always worth when you chase your dream".

\section{Discussion and Conclusions}

The paper entitled "Barriers to and Facilitators of Sports Participation in People with Visual Impairments" (Jaarsma, Dekker, Koopmans, Dijkstra, \& Geertzen, 2014), demonstrates that experiencing visual impairment is a personal barrier by active and inactive participants and it is negatively associated with sports. That paper also demonstrates that active participants need to depend on others to be able to exercise as a personal barrier. In this sense, Javier reported his dependence to be taking to the campus ( 25 $\mathrm{km}$ from home) by a family member, also considered as environmental barrier. Other barriers for Javier were his mobility around the campus at the beginning of his studies or his difficulties to access to some documentary resources. In this process, in the half of his studies, Javier got his guide dog allowing him to gain more independence. Although no comparison is possible with other cases in Spain, we believe that the level of visual impairment did not influence in the level of inclusion during the studies (Holbrook, Kang, \& Morgan, 2013). Other barrier reported by Javier was the extra time required to prepare the courses, especially in those contents that required visual elements, his different learning rhythm or the access to the study materials in comparison with his classmates.

While lack of peers and buddies was perceived as an environmental barrier, acquiring social contacts was mentioned as an important personal facilitator for initiating and maintaining participation in sports (Jaarsma et al., 2014). In the student's opinion, the motivation and entertainment experienced in those five years at the university have been one of the most positive outcomes.

Support from professors was another facilitator mentioned by Javier. Professors used different strategies such as attitudes and values transmission (Elliot, 2008), cooperative learning (Velázquez, 2010), or task adaptations (Reina et al., 2016). In words of the Biomechanics' professor (Fran, 40 yr old): "Javier's inclusion in PASS studies was a challenge for all of us. I did not know how to explain him graphs or motion analysis but the support received by ONCE and the excellent attitude of the student was a facilitator in his learning process. He attended to many tutorship sessions but he reached the basic knowledges and skills required to pass the Sports Biomechanics course". A structured plan of information and guidelines about how to include the student was the basis for a good attitude of the university staff.

Support received by the family is another important environmental facilitator for people with visual impairments (Jaarsma et al., 2014). One year before starting the studies, Javier's mother highlighted her concerns about potential job opportunities for Javier after finishing his studies, and her doubts about the 
viability to study PASS. Also, the ONCE and the Service for students with disabilities expressed their concerns about the adaptations required, especially regarding the sport courses, which required practical skills performance. After finishing his studies, Javier's mum relates: "there were five wonderful years, Javier found a great group of friends who welcomed him as one more in the group, and they helped him all the time. I could personally meet some of the teachers; they were a group of young people highly motivated with the challenge before them. I will never be able to thank them enough for investing their time designing strategies for getting the Degree contents to Javier's "eyes". Thank you very much, thank you all! What I most appreciated was that the demand level asked to Javier, was the same as for the rest of his classmates, it is not right to have a condescending attitude to people with an impairment. But nevertheless, I sometimes wonder if the society is ready to include a person like Javier, giving him the same opportunities according his training".

In July 2014, Javier graduated together with his classmates (Figure 6), and the question of his presence throughout those years at the university was remarked in his classmates' speech as well as in the professor's closing speech. Inclusiveness was achieved thanks to the student's motivation, conviction and his environment that made the student's development possible. He is the first graduate student with a severe visual impairment in PASS Degree in Spain with a full participation in the theoretical and practical courses, thank you to the development of an inclusive learning atmosphere, the improvement of his learning level and the promotion of a positive and inclusive attitude at the university. Javier, frequently expresses his self-satisfaction for finishing the career that some people thought he was not able to do and also for the inclusion feeling that he has always had. He says: "I value very positively my training process. I obtained my degree as any other university fellow. I really hope my case will serve to help to open new potential opportunities for other students with a disability. It is very important that students be able to master any area in the field of Physical Activity and Sport Sciences, being able to cope with their future professional job, allowing that people with functional diversity be part of the decision process regarding the type of physical activity or sport that we would like to practice".

Figure 6. Javier's graduation ceremony

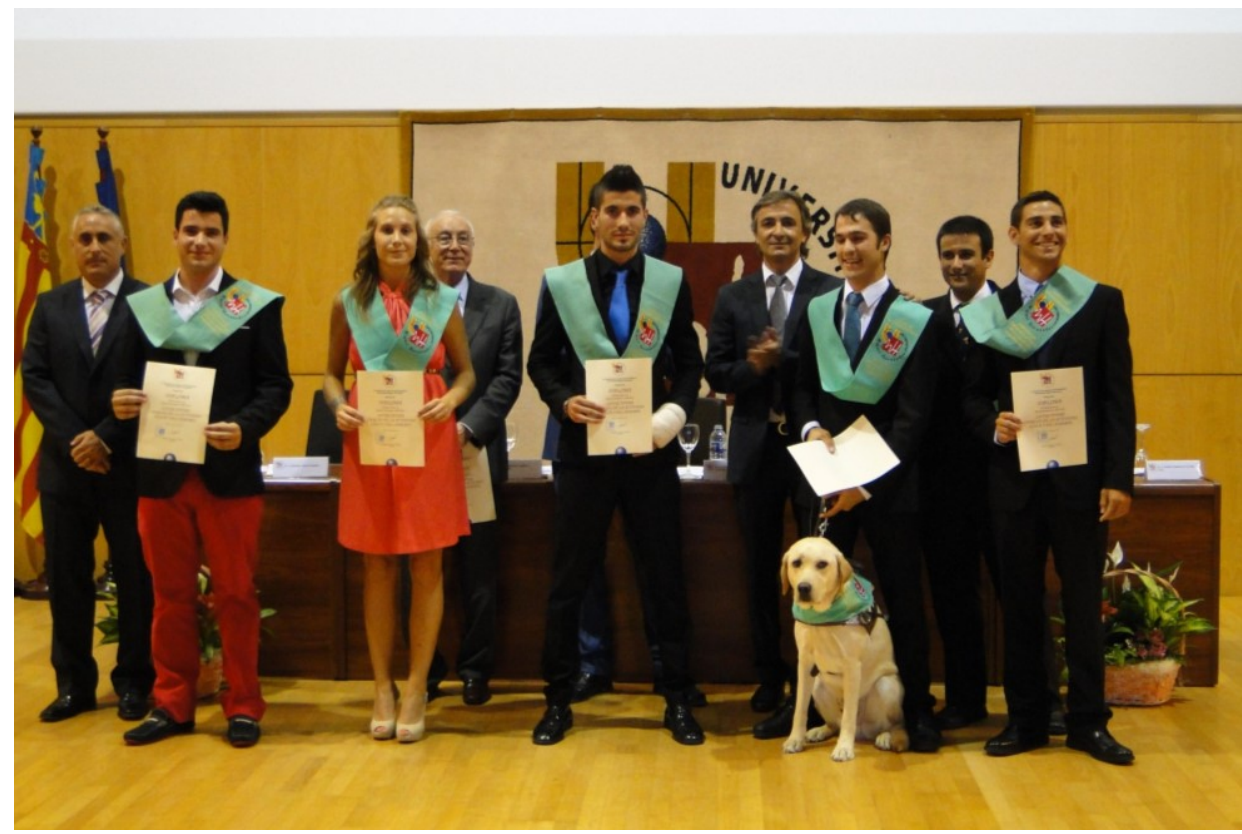


Months later, some students thought that this experience has given to them the chance to deal with the diversity of several working methods to face professional jobs in the future and the best example of how to deal with diversity: "It is said that you will not go to bed without getting to know something new every day". But in this Degree, besides having learned new things, we learnt much more thanks to Javier's help, which has meant a lot to us. A recent interview to one of the frequent Javier's peer tutors revealed (Adrián, 24 years old, Physical Education professor at a primary school): "at this time, after a while since I graduated, I look back and one of the things I am most proud of is to have shared desk with Javier Alvaro. Javier's presence in the class made professors to deal with challenging situations and find creative solutions to make everything accessible for our classmate. Every day with Javier allowed us to learn many new things. In the Adapted Physical Activity course, football, volleyball, judo or swimming were the best examples of how to face students with an impairment in the class. At that moment, I am working with children and adults and I never forget to keep in my bag some blindfolds to work with my participants if one day I have no inspiration to design other activities. It is amazing to listen to four-five years old children expressing their fear of darkness, and how after a session using the blindfolds they ask the day after to play again with them, because for them the masks are a game, but for me is the seal promotion to which I was fortunate to belong".

\section{Acknowledgements}

The authors thank the EUCAPA 2014 Scientific Committee for the award on the best contribution in the area about Inclusion in Physical Education, and the invitation to submit this study case to EUJAPA. Thanks to Javier's mother, Fran and Adrian for their contributions to support the findings about this case study. Thanks also to Alba Roldán for her support in the review of the manuscript and the discussions made to improve some points of the paper.

\section{References}

Block, M. E., \& Obrusnikova, I. (2007). Inclusion in physical education: A review of the literature from 1995-2005. Adapted Physical Activity Quarterly, 24, 103-124.

Block, M. E., Taliaferro, A., Campbell, A. L., Harris, N., \& Tipton, J. (2011). Teaching the self-contained adapted physical education class. Journal of Physical Education, Recreation and Dance, 82(4), 47-52.

DePauw, K. P., \& Doll-Tepper, G. (2000). Toward progressive inclusion and acceptance: Myth or reality? The inclusion debate and bandwagon discourse. Adapted Physical Activity Quarterly, 17, 135-143.

De Salvia, L. (2012). IBSA Classification Rules and Procedures. Extracted 20 April 2016

from

http://www.ibsasport.org/documents/files/ 68-1-IBSA-Classification-Rules-andProcedures.pdf

Elliot, S. (2008). The effect of teacher's attitude toward inclusion on the practice and success levels of children with and without disabilities in physical education. International Journal of Special Education, 23(3), 48-55.

Holbrook, E. A., Kang, M., \& Morgan, D. W. (2013). Acquiring a stable estimate of physical activity in adults with visual impairment. Adapted Physical Activity Quarterly, 30, 59-69.

Horne, M. D. (1983). Elementary classroom teacher attitudes toward mainstreaming. The Exceptional Child, 30, 93-98.

Jaarsma, E. A., Dekker, R., Koopmans, S. A., Dijkstra, P. U., \& Geertzen, J. H. (2014). Barriers to and facilitators of sports participation in people with visual impairments. Adapted Physical Activity Quarterly, 31(3), 240-264.

Kasser, S. L., \& Lytle, R. K. (2005). Inclusive physical activity. $A$ lifetime of opportunities. Champaign, IL: Human Kinetics. 
Lieberman, L. J., Robinson, B., \& Rollheiser, H. (2006). Youth with visual impairments: Experiences within general physical education. RE:view. Rehabilitation and Education for Blindness and Visual Impairment, 38, 35-48.

Lindsay, S., \& Edwards, A. (2013). A systematic review of disability awareness interventions for children and youth. Disability and Rehabilitation, 35(8), 623646.

Lindsay, S., McPherson, A. C., Aslam, H., McKeever, P., \& Wright, V. (2013). Exploring children's perceptions of two school-based social inclusion programs: A pilot study. Child and Youth Care Forum, 42(1), 1-18.

Martin, J. J., \& Smith, K. (2002). Friendship quality in youth disability sport: Perceptions of a best friend. Adapted Physical Activity Quarterly, 19(4), 472482.

Pérez-Tejero, J. (2013). Centro de estudios sobre deporte inclusivo. Cuatro años de fomento del deporte inclusivo a nivel práctico, académico y científico (Education Centre in inclusive sport. Four years of promotion of inclusive sport in practical, academic and scientific levels). Madrid: Universidad Politécnica de Madrid, Sanitas and Psysport.

Reina, R., Sierra-Marroquín, B., GarciaGómez, B., Fernández-Pacheco, Y., Hemmelmayr, I., García-Vaquero, M. P., Campayo-Piernas, M., y Roldán, A. (2016). "Incluye-T". Educación física y deporte inclusivo ("Include yourself": Physical education and inclusive sport). Elche: Limencop.

Ríos, M. et al. (2009). Plan integral para la actividad física y el deporte: Personas con discapacidad (National Plan for the physical activity and sport: People with Disabilities). Extracted, 28 May 2014 from

http://www.csd.gob.es/csd/estaticos/planintegral/discapacidad.pdf.

Rouse, P. (2009). Inclusion in physical education. Champaign, IL: Human Kinetics.

Soler, A., Álvaro, J., Carrasco, E., Cammidge, S. A., Ferrer, J., \& Reina, R. (2013). A new adapted sport: Pètanque for blind and visually impaired. Book of Abstracts: International Symposium of Adapted Physical Activity (p. 144). Istanbul, 19-23 july 2013.

Spanish Paralympic Committee (2014). La inclusión en actividad fisica y deportiva (The inclusion in physical and sporting activity). Barcelona: Paidotribo.

Suomi, J., Collier D., \& Brown, L. (2003). Factors affecting the social experiences of students in elementary physical education classes. Journal of Teaching in Physical Education, 22(2), 186-202.

Thomas, J. R., \& Nelson, J. K. (2001). Research methods in physical activity. Champaign, IL: Human Kinetics.

United Nations (2006). UN Convention on the rights of persons with disabilities and optional protocol 2006. New York: United Nations.

Velázquez, C. (2010). Aprendizaje cooperativo en la Escuela (Cooperative learning at the school). Barcelona: Inde.

Wall, R. (2002). Teachers' exposure to people with visual impairments and the effect on attitudes toward inclusion. $R E$ : view. Rehabilitation and Education for Blindness and Visual Impairment, 34(4), 111-119. 